\title{
Knowledge, Attitude and Practice on the Aesthetic Management of Anterior Teeth Among Dental Undergraduates
}

\author{
Nur Qistina Binti Ahmad Fauzi¹, Dhanraj M Ganapathy² and Revathy Duraiswamy ${ }^{3}$ \\ ${ }^{1}$ Saveetha Dental College and Hospitals, Saveetha Institute of Medical and \\ Technical Science, Saveetha University. Chennai-600077,India \\ ${ }^{2}$ Professor and Head, Department of Prosthodontics, Saveetha Dental College \\ and Hospitals, Saveetha Institute of Medical and Technical Science, \\ Saveetha University, Chennai-600077,India \\ ${ }^{3}$ Senior Lecturer, Department of Prosthodontics, Saveetha Dental College and \\ Hospitals, Saveetha Institute of Medical and Technical Science, Saveetha \\ University Chennai-600077, India
}

\section{ABSTRACT}

Aesthetic management of the anterior teeth is of much importance in the day to day practice of a dentist. In a dental practice, esthetic demand for the anterior teeth is a common complaint put forth by the patients, which is caused by either caries, malformation, anatomic alteration, discoloration/staining as well as hypoplastic defects. The aim of this study is to assess the knowledge, practice and awareness of dental undergraduate students on aesthetic management of anterior teeth. A survey was conducted amongst the undergraduate students in Saveetha Dental College and Hospitals. The questionnaire was prepared and circulated among the undergraduate students. Results were analysed and compared using the SPSS Statistical Software by doing both the frequency tests and correlation tests. A total of 130 students participated in this study of which 28 (21.5\%) were third years, 35 (26.9\%) were final years and the remaining 67 (51.5\%) were interns. The association between year of study and their frequency of doing aesthetic anterior teeth management showed statistical significance ( $\mathrm{p}=0.00)$. Overall, undergraduates of Saveetha Dental College showed a good level of knowledge and awareness in regards to the aesthetic management of anterior teeth.

KEY WORDS: AESTHETIC, ANTERIOR TEETH, KNOWLEDGE, AWARENESS, COMPOSITE, VENEERS..

\section{ARTICLE INFORMATION}

*Corresponding Author: dhanraj@saveetha.com

Received 4th Aug 2020 Accepted after revision 29th Sep 2020

Print ISSN: 0974-6455 Online ISSN: 2321-4007 CODEN: BBRCBA

Thomson Reuters ISI Web of Science Clarivate Analytics USA and Crossref Indexed Journal

$$
\begin{aligned}
& \text { Clarivate } \\
& \text { Analytics }
\end{aligned}
$$




\section{INTRODUCTION}

In recent years, dentistry has seen a notable growth in the emphasis of elective treatment for better aesthetics. As a practice that revolves around the relationship between esthetics and the function of the masticatory components including the surrounding structures, esthetics have become the basis of surgical, restorative and corrective procedures. (Gordan, Abu-Hanna and Mjör, 2004)With the increase in demand of anterior teeth restorations as well as the heightened media emphasis for a better smile, aesthetics have become a priority for both patients and dentists. (Gordan, Abu-Hanna and Mjör, 2004; Ahmad, 2005b).

A pleasing appearance plays as an important factor of success for both an individual's personal and professional lives. (Gupta et al., 2016)(Ahmad, 2005b) An attractive or pleasing smile greatly influences the extent of attractiveness and personality that a person possesses. In a dental practice, esthetic demand for the anterior teeth is a common complaint put forth by the patients, which is caused by either caries, malformation, anatomic alteration, discoloration/staining as well as hypoplastic defects.(Moskowitz and Nayyar, 1995)

Aesthetic management of the anterior teeth is of much importance in the day to day practice of a dentist. Anterior dental esthetics can be grouped into facial, dental as well as gingival components. Facial esthetics specifically includes the integration of an individual's facial features and the use of dental restorations with that of the existing skeletal and soft tissue features. The purpose of doing so is to boost desirable qualities or acts as a method to distract attention away from undesirable abnormalities. (Ahmad, 2005b)On the other hand, dental esthetics comprises the shape, size, colour, position of teeth and their inter and intra arch relationships. The relationship between these extraoral and intraoral components have an affect on the dental treatment provided. Thus, appropriate knowledge on its relation and its subsequent application towards the practice plays a significant role in providing a quality dental treatment. (Ahmad, 2005a)

The aim of this study is to assess the knowledge, practice and awareness of dental undergraduate students on aesthetic management of anterior teeth. The purpose being that by determining the degree of their understanding, a better form of practice can be integrated into their daily practice in the future. Previously our department has published extensive research on various aspects of prosthetic dentistry ('Evaluation of Corrosive Behavior of Four Nickel-chromium Alloys in Artificial Saliva by Cyclic Polarization Test:An in vitro Study', 2017; Ganapathy, Kannan and Venugopalan, 2017; Jain, 2017a, 2017b; Ranganathan, Ganapathy and Jain, 2017; Ariga et al., 2018; Gupta, Ariga and Deogade, 2018; Anbu et al., 2019; Ashok and Ganapathy, 2019; Duraisamy et al., 2019; Varghese, Ramesh and Veeraiyan, 2019), this vast research experience has inspired us to research about the knowledge, attitude and practice on the aesthetic management of anterior teeth among dental undergraduates.

\section{MATERIAL AND METHODS}

Study Setting: This cross-sectional study was done among undergraduate students (includes third years, final years, interns) of Saveetha Dental College and Hospitals. A total of 130 students participated in this study.

Study Subjects: A total of 130 students participated in this study of which 28 (21.5\%) were third years, 35 $(26.9 \%)$ were final years and the remaining 67 (51.5\%) were interns.

Methodology: A survey was conducted through an online standard questionnaire with 15 multiple choice questions sent via a Google Form application. The questionnaire consisted of questions about the knowledge, awareness and practice regarding aesthetic anterior teeth management. Adequate time was provided to fill the questionnaire. The responses of the students were recorded, analysed for flaws, checked for completeness and were taken up for assessment.

Statistical Analysis: After data was collected and coded, the statistical analysis was done using IBM SPSS Statistical Software package (Version 23.0). All the frequency tests were carried out and the Chi-square test was done at a significance level.

\section{RESULT AND DISCUSSION}

A total of 130 students participated in the study, which consisted of $89(68.5 \%)$ females and 41 (31.5\%) males. [Figure 1] The students included 28 (21.5\%) third years, 35 (26.9\%) final years and the remaining 67 (51.5\%) interns. [Figure 2] When enquired about whether they commonly practice aesthetic anterior managements, 43 (33.1\%) participants admitted that they do, 66 (50.8\%) participants admitted that they somewhat do and 21 (16.2\%) admitted that they do not. [Figure 3].

Figure 1: This pie chart depicts the gender of the undergraduate students. $68.5 \%$ of the respondents were females. $31.5 \%$ of the respondents were males.

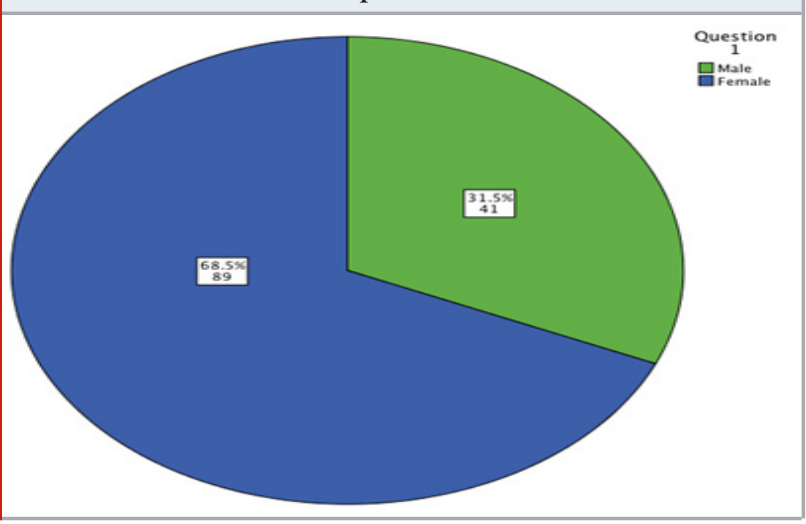


Figure 2: Pie chart showing responses to the question among the undergraduates based on their year of study. $21.5 \%$ of the respondents were third years. $26.9 \%$ of the respondents were final years. 51.5\% of the respondents were interns.

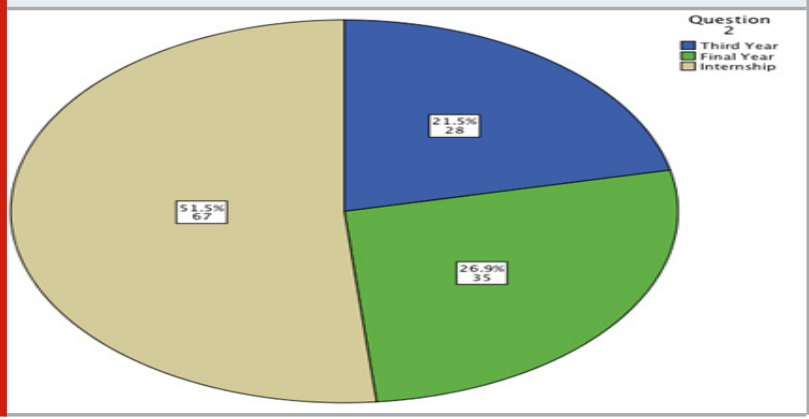

Figure 3: Pie chart showing responses to the question, "Do you commonly do aesthetic anterior teeth management during your practice?". About 50.8\% of the respondents stated that they commonly practice aesthetic anterior teeth management.

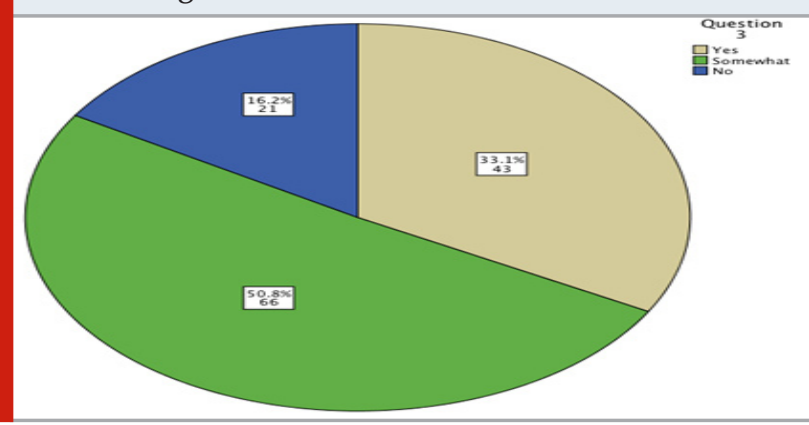

Figure 4: Pie chart showing responses to the question, "Which type of aesthetic management are you most confident in doing?". About $86.2 \%$ of the respondents stated that they were most confident in composite restorations.

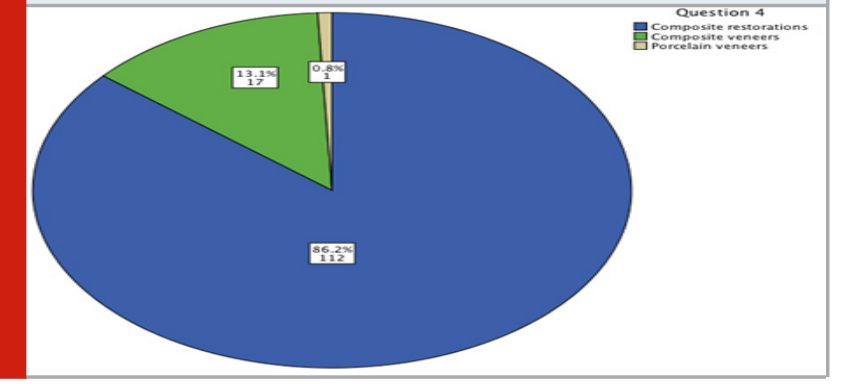

In regards to the type of aesthetic management that they are most confident in doing, 112 (86.2\%) participants agreed that it was composite restorations, 17 (13.1\%) participants agreed that it was composite veneers and only $1(0.8 \%)$ agreed that it was porcelain veneers. [Figure 4] When questioned about the importance of rubber dam usage during anterior composite restorations, $79(60.8 \%)$ participants believed that is it necessary, $43(33.1 \%)$ participants believed that it is somewhat necessary while $8(6.2 \%)$ participants agreed that it is not necessary. [Figure 5] In terms of shade selection, 77 (59.2\%) participants agreed that it should be done before the placement of anterior restorations, 43 (33.1\%) participants were unsure that it should be done before while $10(7.7 \%)$ believed it not to be so. [Figure 6].

Figure 5: Pie chart showing responses to the question, "Is the usage of rubber dam required during anterior composite restorations?". About $60.8 \%$ of the respondents agreed that rubber dam is necessary in anterior composite restorations.

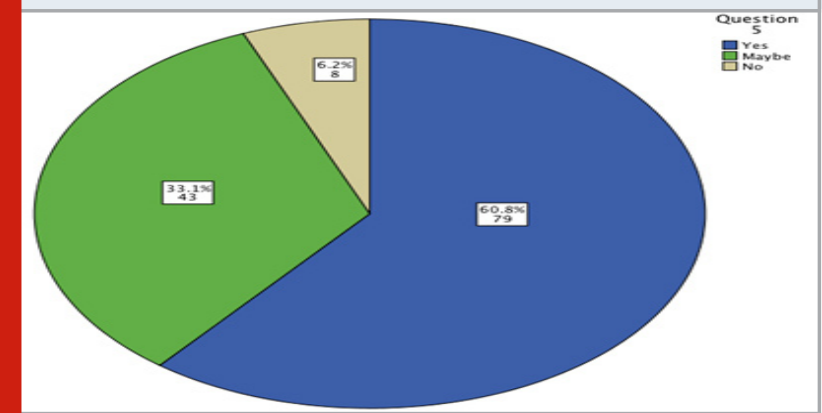

Figure 6: Pie chart showing responses to the question, "Is shade selection done before the placement of anterior restorations?". About 59.2\% of the respondents believed that shade selection should be done before the placement of anterior restorations.

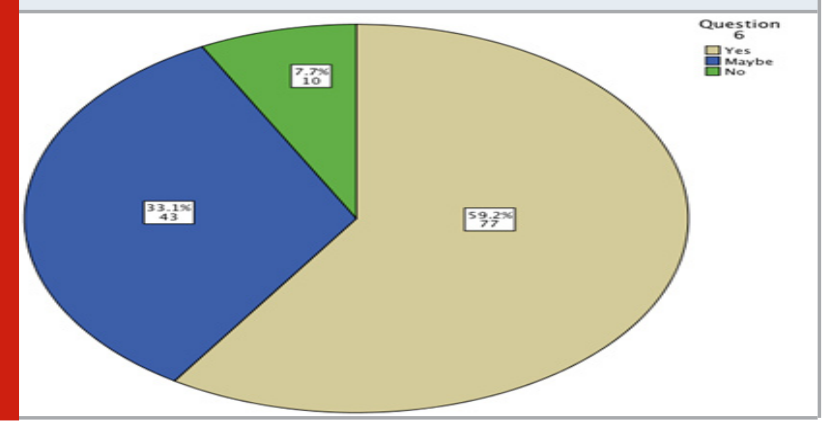

Figure 7: Pie chart showing responses to the question, "Is composite resin the best choice for anterior restorations?". About $43.8 \%$ of the respondents agreed that composite resin is the best choice for anterior restorations.

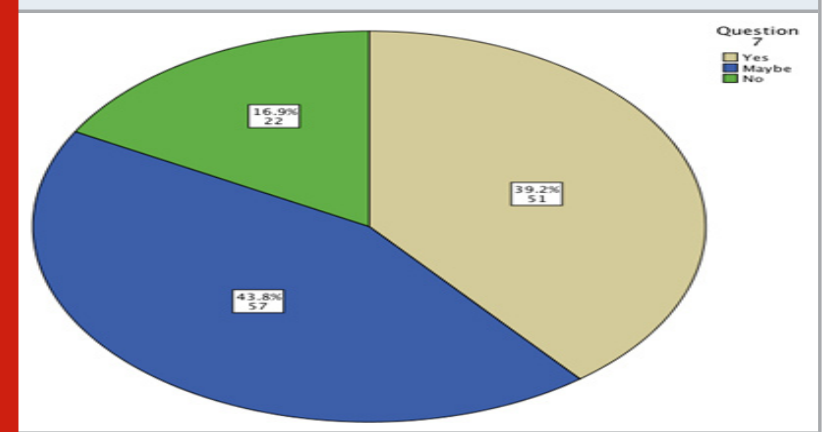

When questioned on whether composite resin is the best choice for anterior restorations, 51 (39.2\%) participants agreed that it was the best choice, 57 (43.8\%) were unsure about the statement while 22 (16.9\%) participants agreed 
that it was not the best choice. [Figure 7] Analysation of which type of composite was preferred for anterior aesthetic restoration found that $26(20.0 \%)$ agreed that it is microhybrid composite, 57 (43.8\%) participants agreed that it is microfilled composite, 17 (13.1\%) participants agreed that it is nanofilled composite while the remaining $30(23.1 \%)$ didn't know which was the best. [Figure 8].

Figure 8: Pie chart showing responses to the question, "Which type of composite is preferred for anterior aesthetic restorations?". About 43.8\% of the respondents agreed that microfilled composite is the most preferred.

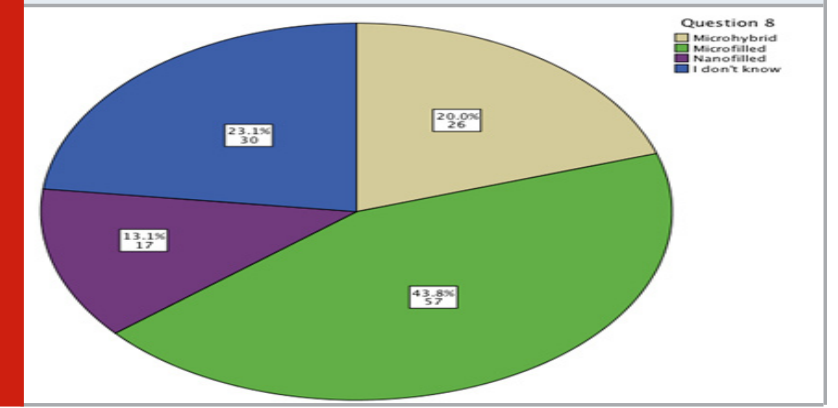

Figure 9: Pie chart showing responses to the question, "Are you aware of the 'natural layering concept' in direct composite restorations?". About $64.6 \%$ of the respondents stated that they were not aware of the "natural layering concept'.

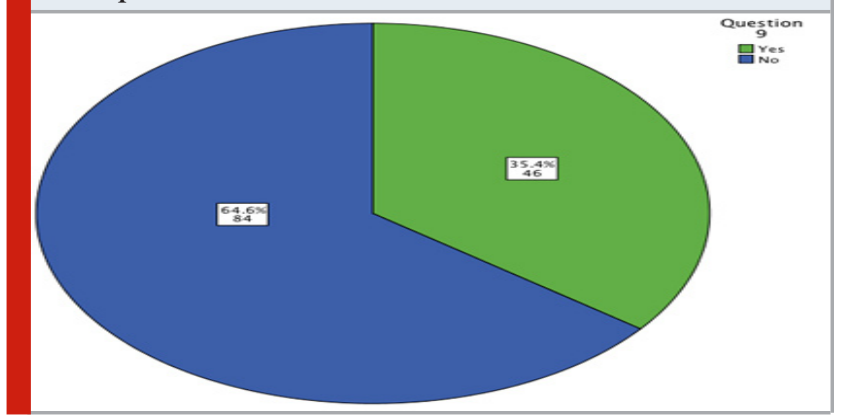

Figure 10: Pie chart showing responses to the question, "In cases of midline diastema, which method is usually preferred?". About 56.2\% of the respondents agreed that in midline diastema, direct composite veneer is the preferred option.

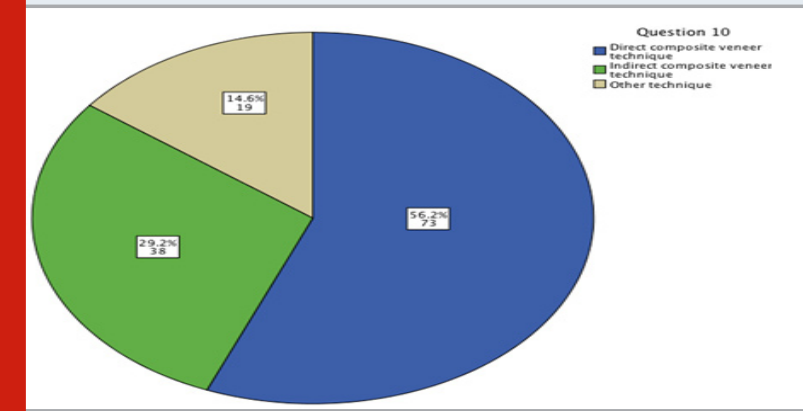

Assessment on their awareness about the natural layering concept showed that 46 (35.4\%) admitted that they were aware of the concept while 84 (64.6\%) participants admitted that they were not aware of the concept. [Figure 9] In cases of midline diastema, 73 (56.2\%) believed that direct composite veneer is the preferred method while 38 (29.2\%) participants believed it to be indirect composite veneer technique and 19 (14.6\%) participants believed it to be other techniques. [Figure 10] When inquired about in which clinical situation would direct veneers are preferred, 84 (64.6\%) participants agreed that it was Ellis Class I, 24 (18.5\%) participants believed it to be in Ellis Class II cases while $22(16.9 \%)$ participants agreed that it was Ellis Class III. [Figure 11].

Figure 11: Pie chart showing responses to the question, "In which clinical situation is direct veneers usually preferred?". About $64.6 \%$ of the respondents stated that direct veneers are usually preferred in Ellis Class I cases.

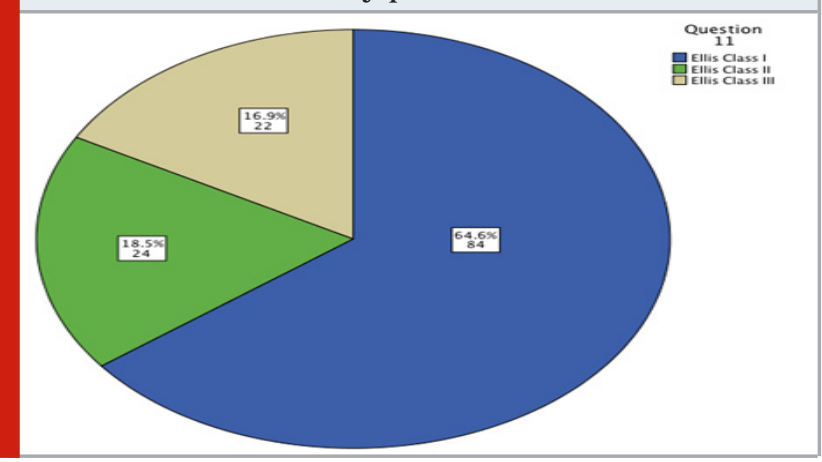

In regard to their personal usage of LED light for composite restorations, 97 (74.6\%) participants admitted that they primarily use it while 33 (25.4\%) participants admitted that they did not primarily use it. [Figure 12] When questioned about the time period in which finishing and polishing should be done, 71 (54.6\%) participants agreed that it should be done immediately, 41 (31.5\%) participants agreed that it should be done within 24 hours while 18 (54.6\%) participants believed it should be done within 7 days. [Figure 13].

Figure 12: Pie chart showing responses to the question, "Do you primarily use LED light for curing composite restorations?". About $74.6 \%$ of the respondents primarily use LED light for composite restorations.

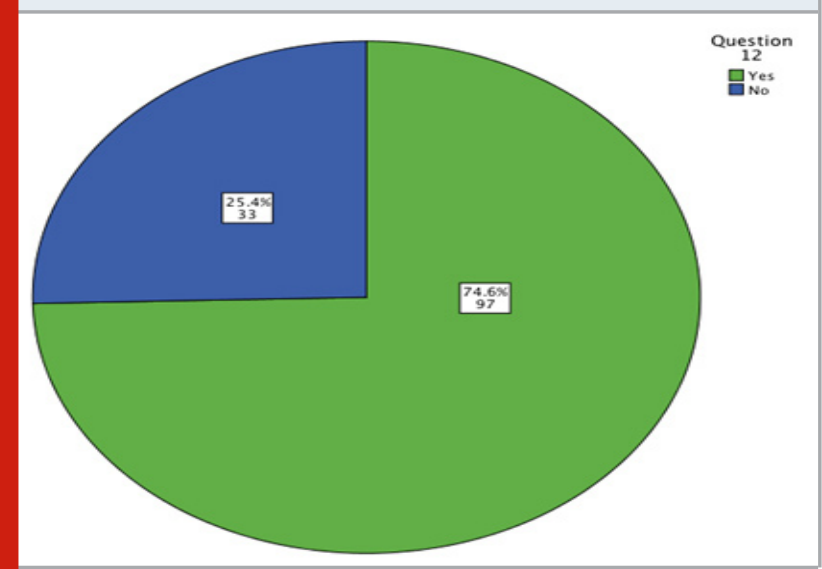


Figure 13: Pie chart showing responses to the question, "When is the time period in which finishing and polishing should be done?". About 54.6\% of the respondents agreed that finishing and polishing should be done immediately.

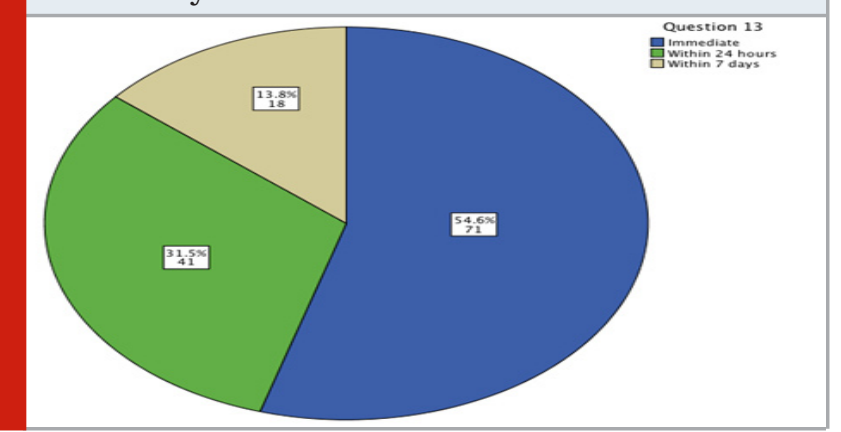

Analysation of the reason composite resins and porcelain materials are generally preferred in aesthetic procedures showed that $54(41.5 \%)$ participants stated it was the high endurance to stretching, breaking and chemicals while 24 (18.5\%) participants stated that it was because of the low rate of abrasion to the opposite teeth and 52 $(40.0 \%)$ participants agreed that these materials have higher transparency. [Figure 14] Overall, 81 (62.3\%) participants admitted that they need more knowledge on aesthetic management for anterior teeth management while 49 (37.7\%) participants believed that it was not necessary. [Figure 15].

Figure 14: Pie chart showing responses to the question, "Why are composite resins and porcelain materials generally preferred in aesthetic procedures?”. About 41.5\% of the respondents agreed that it is preferred for its high endurance to stretching, breaking and chemicals.

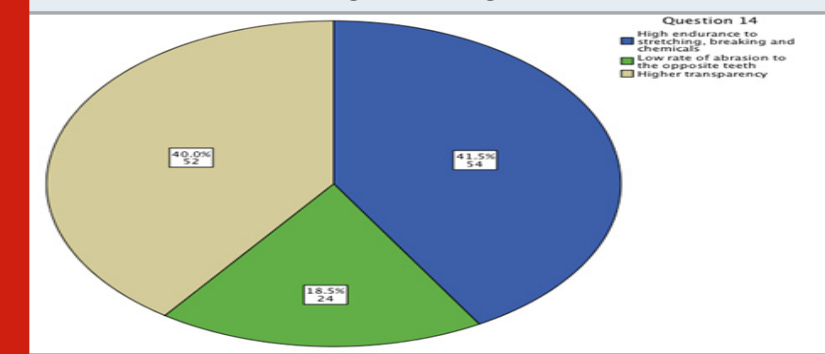

Figure 15: Pie chart showing responses to the question, "Do you think you require more knowledge on aesthetic management for anterior teeth?". About 62.3\% of the respondents believed that they need more knowledge on the aesthetic management for anterior teeth.

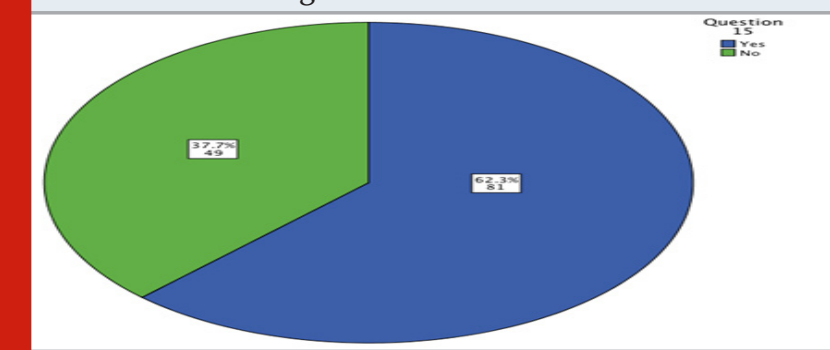

When the year of study was correlated with their frequency of doing aesthetic anterior teeth management, it showed statistical significance between the two $(\mathrm{p}=0.00)$. Interns have been shown to practice more aesthetic treatments for the anterior teeth. [Figure 16].

Figure 16: Bar chart showing comparison of responses based on the year of study to the question, "Do you commonly do aesthetic anterior teeth management in your practice?". X-axis represents the year of study and Y-axis represents the percentage of participants. There is a significant correlation between the year of study and their frequency in practicing aesthetic anterior teeth management (Chi-square test; $\mathrm{p}$-value $=\mathbf{0 . 0 0}$-significant). Interns have been shown to practice more aesthetic treatments for the anterior teeth.

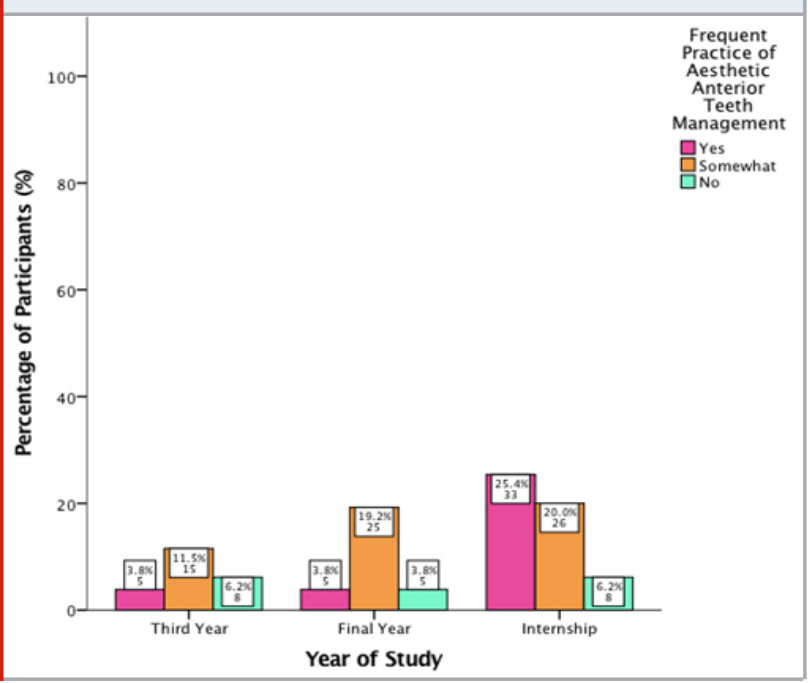

The study was conducted to assess the knowledge about anterior aesthetics management among undergraduates. Majority of the participants agreed that rubber dam is necessary especially for anterior teeth restorative procedures. When rubber dam is used, it provides a drier field of operation, which in turn prevents moisture contamination that has been known to impair particularly adhesive procedures. (Baldissera et al., 2013) Although it is deemed necessary, its application further increases the complexity of the restorative technique and the patient's chair time as well as the price of the restorations. (Lima et al., 2009) However, many studies have stated that the usage of rubber dams have greatly influenced the longevity of the restoration. (Baldissera et al., 2013).

According to this study, the majority of participants believed that microfilled composite is the most efficient in aesthetic restorations. Microfilled composite was developed in such a way that it produces a smoother surface and its similarity to the enamel helps increase the aesthetic appearance of the teeth. (Barbosa et al., 2005) On the other hand, nanohybrids are actually a newer developed material that have shown to provide even more advantages when compared to microhybrid composites. (Moraes et al., 2009; Saunders and Saunders, 2009). 
More than half of the participants are not aware of the 'natural layering concept'. Natural layering concept is considered a relatively simple yet effective method of producing highly aesthetic direct restorations. This concept embraces an optical and anatomical characteristic that more accurately represents natural teeth. It follows two basic steps which includes the selection of dentin chroma in the cervical area and the selection of enamel tint.(Oral Health-, 2007) In this study, most of the participants primarily use LED lights for curing composite restorations. LED units require less monitoring as it is able to stabilize the irradiance for a prolonged duration. Compared to QTH units, this alternative requires mandatory monitoring which needs to be performed weekly. (Saunders and Saunders, 2009) (Hao et al., 2015)

\section{CONCLUSION}

Within the limits of the study, undergraduates of Saveetha Dental College showed a good level of knowledge and awareness in regards to the aesthetic management of anterior teeth. Overall, they have shown a profound interest in learning more about this topic and implementing it in their practice.

\section{ACKNOWLEDGEMENTS}

The study was supported by Saveetha Dental College and Hospitals, Saveetha Institute of Medical and Technical Science, Chennai.

Conflict of Interest: There were no conflicts of interest.

\section{REFERENCES}

Ahmad, I. (2005a) 'Anterior dental aesthetics: Dental perspective', British Dental Journal, pp. 135-141. doi: 10.1038/sj.bdj.4812569.

Ahmad, I. (2005b) 'Anterior dental aesthetics: Facial perspective', British Dental Journal, pp. 15-21. doi: 10.1038/sj.bdj.4812534.

Anbu, R. T. et al. (2019) 'Comparison of the Efficacy of Three Different Bone Regeneration Materials: An Animal Study', European journal of dentistry, 13(1), pp. 22-28.

Ariga, P. et al. (2018) 'Determination of Correlation of Width of Maxillary Anterior Teeth using Extraoral and Intraoral Factors in Indian Population: A Systematic Review', World Journal of Dentistry, 9(1), pp. 68-75.

Ashok, V. and Ganapathy, D. (2019) 'A geometrical method to classify face forms', Journal of oral biology and craniofacial research, 9(3), pp. 232-235.

Baldissera, R. A. et al. (2013) 'Are there universal restorative composites for anterior and posterior teeth?', Journal of Dentistry, pp. 1027-1035. doi: 10.1016/j. jdent.2013.08.016.

Barbosa, S. H. et al. (2005) 'Effect of different finishing and polishing techniques on the surface roughness of microfilled, hybrid and packable composite resins', Brazilian Dental Journal, pp. 39-44. doi: 10.1590/ s0103-64402005000100007.

Duraisamy, R. et al. (2019) 'Compatibility of Nonoriginal Abutments With Implants: Evaluation of Microgap at the Implant-Abutment Interface, With Original and Nonoriginal Abutments', Implant dentistry, 28(3), pp. 289-295.

Evaluation of Corrosive Behavior of Four Nickelchromium Alloys in Artificial Saliva by Cyclic Polarization Test:An in vitro Study' (2017) World Journal of Dentistry, 8(6), pp. 477-482.

Ganapathy, D. M., Kannan, A. and Venugopalan, S. (2017) 'Effect of Coated Surfaces influencing Screw Loosening in Implants: A Systematic Review and Meta-analysis', World Journal of Dentistry, 8(6), pp. 496-502.

Gordan, V. V., Abu-Hanna, A. and Mjör, I. A. (2004) 'Esthetic dentistry in North American dental schools', Journal, 70(4), p. 230.

Gupta, P., Ariga, P. and Deogade, S. C. (2018) 'Effect of Monopoly-coating Agent on the Surface Roughness of a Tissue Conditioner Subjected to Cleansing and Disinfection: A Contact Profilometric Study', Contemporary clinical dentistry, 9(Suppl 1), pp. S122S126.

Gupta, R. et al. (2016) 'Experience from Classroom Teaching to Clinical Practice Regarding Shortened Dental Arch (SDA) Concept Among Dentists - A Questionnaire Study', Journal of clinical and diagnostic research: JCDR, 10(12), pp. ZC27-ZC32.

Hao, X. et al. (2015) 'A survey of power density of lightcuring units used in private dental offices in Changchun City, China', Lasers in Medical Science, pp. 493-497. doi: 10.1007/s 10103-013-1351-0.

Jain, A. R. (2017a) 'Clinical and Functional Outcomes of Implant Prostheses in Fibula Free Flaps', World Journal of Dentistry, 8(3), pp. 171-176.

Jain, A. R. (2017b) 'Prevalence of Partial Edentulousness and Treatment needs in Rural Population of South India', World Journal of Dentistry, 8(3), pp. 213-217.

Lima, F. G. et al. (2009) 'Influence of microleakage, surface roughness and biofilm control on secondary caries formation around composite resin restorations: an in situ evaluation', Journal of Applied Oral Science, pp. 61-65. doi: 10.1590/s1678-77572009000100012.

Moraes, R. R. et al. (2009) 'Nanohybrid Resin Composites: Nanofiller Loaded Materials or Traditional Microhybrid Resins?', Operative Dentistry, pp. 551-557. doi: 10.2341/08-043-1.

Moskowitz, M. E. and Nayyar, A. (1995) 'Determinants of dental esthetics: a rational for smile analysis and 
treatment', The Compendium of continuing education in dentistry, 16(12), pp. 1164, 1166, passim; quiz 1186.

Oral Health- (2007) Clinical Application of the "Natural Layering Concept' - Oral Health Group, Oral Health Group. Available at: https://www.oralhealthgroup.com/ features/clinical-application-of-the-natural-layeringconcept/ (Accessed: 3 July 2020).

Ranganathan, H., Ganapathy, D. M. and Jain, A. R. (2017) 'Cervical and Incisal Marginal Discrepancy in Ceramic Laminate Veneering Materials: A SEM Analysis', Contemporary clinical dentistry, 8(2), pp.
272-278.

Saunders and Saunders (2009) 'Current practicality of nanotechnology in dentistry. Part 1: Focus on nanocomposite restoratives and biomimetics', Clinical, Cosmetic and Investigational Dentistry, p. 47. doi: 10.2147/cciden.s7722.

Varghese, S. S., Ramesh, A. and Veeraiyan, D. N. (2019) 'Blended Module-Based Teaching in Biostatistics and Research Methodology: A Retrospective Study with Postgraduate Dental Students', Journal of dental education, 83(4), pp. 445-450. 